\title{
Nota Técnica: \\ Los embarcaderos británicos de hierro en el siglo XIX. El descubrimiento de nuevos materiales
}

\author{
Technical Note: \\ The development of iron British piers in the XIX century. \\ The discovery of new materials
}

\author{
C. González-García de Velasco(*), M. González-Vílchez(*)
}

Recepción/Received: 15-I-10

Aceptación/Accepted: $30-\mathrm{IV}-10$

\section{RESUMEN}

Se estudia en el presente artículo cómo los embarcaderos de madera iban languideciendo a partir de mediados del siglo XIX, aquejados especialmente por los ataques de invertebrados. Pronto, en los embarcaderos británicos, la madera iba a ser sustituida por el hierro, en la versión de dos nuevos materiales, la fundición y el hierro forjado.

La fundición poseía una gran resistencia a la compresión, aunque poca a la tracción y a la flexión. Tampoco permitía la soldabilidad, pero presentaba un comportamiento magnífico frente a la corrosión, siendo muy utilizada para pilares en los nuevos embarcaderos. El hierro forjado presentaba menor resistencia a la corrosión pero, en cambio, ofrecía altas prestaciones a tracción y flexión, lo que lo hacía muy valioso para su colocación en vigas y forjados en los muelles. De la combinación de ambos materiales resultó el gran éxito habido en la construcción de puentes y embarcaderos metálicos, a partir de 1850.

Palabras clave: embarcaderos británicos, fundición, hierro forjado, resistencia de materiales, corrosión.

\section{SUMMARY}

In this article, the authors study the decadence of wood piers along XIX century, mainly because of problems inherent to the attacks of invertebrates. Soon, the wood structures will be substituted by iron ones, appearing two extraordinary materials, cast iron and wrought iron.

Cast iron was a material with a great compression resistance, but weak for traction and flexion. It was not welding, but its resistance to the corrosion was notable, because of it, was very used at piles of British sea piers. On the contrary, wrought iron offered high conditions for traction and flexion, so it appeared like a very useful material to make girders and joists, but suffering the problem of a lack of resistance to corrosion. The combination of both materials supposed a great success in the construction of bridges and piers, since 1850.

Keywords: British piers, cast iron, wrought iron, materials resistance, corrosion.

(*) Universidad de Sevilla (España). 


\section{INTRODUCCIÓN Y OBJETIVOS}

El fenómeno de la aparición a mediados del siglo XIX de los embarcaderos de hierro en Gran Bretaña está ligado a la problemática que la madera conllevaba y que obligaba al descubrimiento de nuevos materiales exentos de los problemas que planteaba el uso estructural de la madera en el medio marino. La aplicación de la fundición y del hierro forjado en la construcción de puentes y muelles (hasta entonces estos materiales solo se habían usado para fabricar armas y herramientas) abre un camino de extraordinario interés, que desembocará muy pronto en la utilización de las estructuras de acero en el campo de la construcción de obras de ingeniería y arquitectura, sustituyendo a la madera y los sistemas tradicionales de muros de carga.

Se pretende en el presente trabajo poner de manifiesto la importancia de la fundición y el hierro forjado, materiales extraordinarios, especialmente en el mundo de los embarcaderos, y se exponen las características resistentes que los mismos tuvieron en los inicios de esta nueva tecnología, así como la actualidad de la que todavía disfrutan en el mundo de la ingeniería y la construcción modernas.

\section{ANTECEDENTES}

Las maderas de roble, abeto, pino y haya, que existían en Gran Bretaña en abundancia, eran más o menos atacables por los devoradores de madera que se encontraban en el agua salada y, pronto, muchos embarcaderos británicos construidos en madera empezaron a sucumbir, algunos a poco de ser construidos, entre ellos los de Southend y Herne Bay, este último diseñado y construido en 1832 por el prestigioso ingeniero Thomas Telford en los últimos años de su vida, y que se arruinó siete años después de ser inaugurado (1).

El futuro de los muelles de madera era sombrío. Al peligro de ataque de invertebrados como teredos y limnorias se unía el del fuego, que dañó a muchos de ellos. Aunque algunos embarcaderos de madera duraron muchos años, la mayoría de ellos tuvieron una vida efímera, dependiendo de la clase de madera empleada (2). Finalmente, todos los muelles de madera construidos en Gran Bretaña en el siglo XIX desaparecieron, algunos sustituidos por otros de hierro.

Según T. Mickleburg (3), el mayor experto contemporáneo en embarcaderos en Gran Bretaña, el primer muelle que se construyó completamente en estructura metálica, con pilares de fundición y vigas de hierro forjado, fue el Margate Pier, diseñado por Eugenius Birch en 1853, aplicándose en él además el descubrimiento de Alexander
Mitchell, los pilotes roscados de fundición. Esta aseveración de primogenitura del muelle de Margate no es exacta y los autores de este trabajo han constatado que el propio Mitchell construyó con anterioridad, en 1847, el muelle de Courtown, en Waxford (4), de pilotes y vigas de fundición, con el sistema de cimentación de helicoides roscados inventado y patentado por él (Figura 1). También el muelle de Milton on Thames, en Gravesend, proyectado por John B. Redman en 1843, se ejecutó totalmente en fundición, aunque con cimentación por pozos entibados.

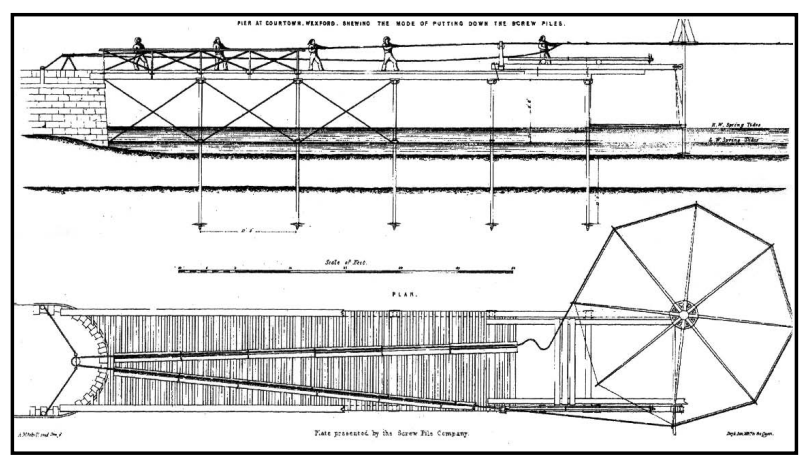

Figura 1. Muelle de Courtown en Waxdorf.

Coincidió este inicio de los embarcaderos metálicos (mediados del siglo XIX) con el esplendor del Imperio británico, en el largo periodo de monarquía de la reina Victoria, que se extendería hasta final de siglo. El turismo de interior hacia la costa era creciente, impulsado por la buena marcha de la economía británica y el auge y extensión de la red ferroviaria, y por todas partes surgieron compañías explotadoras de muelles de recreo, que estaban dispuestas a estudiar y obtener concesiones para levantar embarcaderos metálicos en las costas. Solamente el principal autor de estos muelles de hierro, el ya citado ingeniero Eugenius Birch, llegó a levantar 14 de ellos en diferentes lugares de la costa inglesa. Durante la década de 1860 se construyeron 22 muelles, y hasta 1914 , inicio de la Primera Guerra Mundial, se erigieron un total de 85 embarcaderos de hierro. El más antiguo de los muelles metálicos supervivientes al día de hoy es el de Southport, el tercer embarcadero metálico que se construyó, en el año 1859, proyectado por J. Brunlees.

\section{LA APARICIÓN DE DOS MATERIALES EXTRAORDINARIOS: LA FUNDICIÓN Y EL HIERRO FORJADO}

En la prehistoria, el hierro ya se obtenía en hornos calentados con carbón vegetal. El metal se obtenía en estado pastoso, no fluido, al no alcanzarse las temperaturas adecuadas, y la escoria debía ser eliminada por golpeo o forja. En la Edad Media se mejoraron los hornos, llegándose 
a los denominados hornos de cuba, hornos bajos y forjas catalanas. Se conocía la fundición desde la antigüedad, pero era un subproducto poco adecuado para espadas y armas, ya que no admitía la forja. A principios del siglo XV ya se conocían hornos de fundición líquida y el consumo de madera para los hornos fue tan intenso que algunos gobiernos empezaron a prohibir la tala indiscriminada. El desarrollo industrial de la minería de carbón en los inicios del siglo XVIII, y su transformación en coque por destilación a partir de 1735 , permitió llegar a temperaturas más altas, con un combustible barato y abundante, lo que iba a permitir fabricar hierro puro (hierro dulce) y las variedades o combinaciones de hierro y carbono que darían paso a la siderurgia moderna.

La fundición no era, por tanto, un material nuevo en el siglo XVIII, pero no fue empleada en estructuras de puentes hasta finales de dicho siglo en Inglaterra, en el magnífico puente de Coalbrookdale (1779), que luego dio nombre al pueblo de Iron Bridge, afortunadamente conservado hoy, y catalogado como Patrimonio de la Humanidad (Figura 2). Abraham Darby, fundador de la fundición de Coalbrookdale, había reemplazado el carbón vegetal por carbón de hulla y había abierto el camino a la fundición gris, que implicaría la revolución de las estructuras en el siglo XIX. Por aquella época, Wilkinson aplica la fundición a las nuevas máquinas, colaborando con Watt para llevar a la práctica la primera máquina de vapor (5). El propio Wilkinson diseñó el ya citado puente de Coalbrookdale, ayudado por el arquitecto T. Pritchard, y llevando a cabo la fundición del mismo en la fábrica de los Darby.

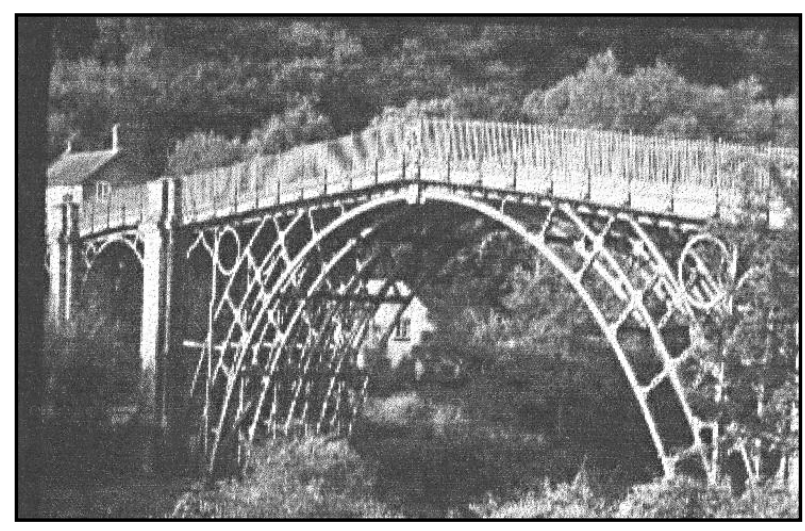

Figura 2. El puente Iron Bridge, en Coalbrookdale.

\section{CARACTERÍSTICAS Y PROPIEDADES DE LA FUNDICIÓN}

La fundición o hierro fundido es una aleación de hierro y carbono, procedente directamente de la fusión del mineral de hierro en altos hornos, con una proporción de carbono de entre un $2 \%$ y un $4,5 \%$. Habitualmente contiene también hasta un $4 \%$ de silicio y proporciones inferiores de manganeso, azufre y fósforo. Estos componentes, principalmente el carbono y el silicio, que son en realidad impurezas del hierro que pueden eliminarse en un segundo proceso metalúrgico, confieren al hierro fundido o colado, unas cualidades específicas que lo distinguen de otras variedades de hierro.

Dependiendo de la composición química, del contenido de carbono y del proceso de enfriamiento, se diferencian diversos tipos de hierro fundido, siendo el más interesante el conocido como fundición gris, en la que el carbono se encuentra principalmente en forma de grafito, y que es la que se empleó durante el siglo XIX en estructuras de edificios, puentes y embarcaderos. Las cualidades más importantes son su resistencia a la oxidación, su capacidad de trabajar a compresión y su bajo punto de fusión, que hace que se pueda fundir fácilmente y verter en moldes. Entre los inconvenientes está su fragilidad, su escasa resistencia a tracción y flexión, y la dificultad que presenta para la soldadura.

La fundición, en su aplicación a las estructuras, ha decaído mucho desde aquella época hasta nuestros días, sustituida por el acero. Pero existe una corriente recuperadora de este material, cuyo comportamiento frente a la corrosión es magnífico y cuyas cualidades pueden mejorarse con tratamientos complementarios.

En un trabajo reciente del ingeniero británico W. Rooker (6), director de la ya citada Fundición Coalbrookdale (empresa británica de más de dos siglos de antigüedad, que se mantiene todavía en activo), se indica que la fundición del tipo de grafito esferoidal tiene además la propiedad de dejarse soldar y posee una relativa ductilidad. Además, se afirma que la corrosión en ambiente marino, ya de por sí baja en el hierro fundido, se puede disminuir mediante el recubrimiento del pilote de fundición con aluminio fundido, un elemento que funciona como ánodo de protección en la electrolisis, dejando un producto de corrosión superficial denso y fuertemente adherido, que protege al pilote de fundición.

Por otra parte, D. A. Allwood (7), director de la compañía Widnes Foundry and Engineering (otra compañía británica centenaria, fundada en 1842 y dedicada todavía a la fundición), informa que la incorporación de una pequeña cantidad (2\%) de níquel o cromo al hierro fundido mejora la resistencia a la corrosión de este en condiciones alcalinas y ácidas, y también ante cloruros marinos.

La fundición constituía, pues, un material excelente, que podía soportar diez veces más carga que la madera, que podía utilizarse en el ambiente agresivo del agua del mar y que se moldeaba a voluntad y diseño del autor. La 
investigación que se desarrolló alrededor de los muelles metálicos hizo avanzar su tecnología a pasos agigantados. Aparecieron máquinas de hincado, de inyección de agua o de roscado de pilotes. Se diseñaron barras de atado que se atornillaban a orejetas u ojales incorporados al pilote (Figura 3), se resolvieron los problemas de ajuste vertical de tramos contiguos, y otros relativos a continuidad de soportes, etc.

En algunos de los primeros muelles se diseñaron también las vigas y riostras de fundición, aunque posteriormente los elementos a tracción se diseñarían en hierro forjado. Apareció todo un mundo de imaginación decorativa en los elementos de equipamiento, tales como bancos, barandillas, casetas, kioskos y pabellones (Figura 4). La fundición encontró su campo de desarrollo en la tecnología que los ingenieros británicos crearon para diseñar los embarcaderos metálicos y sus sistemas constructivos, y alcanzó un esplendor no imaginado. Por ejemplo, la fundición de Coalbrookdale, hoy día todavía en activo, con 200 empleados y una producción de 150 toneladas de fundición a la semana, a mediados del siglo XIX tenía 5.000 empleados y producía alrededor de 3.000 toneladas a la semana.

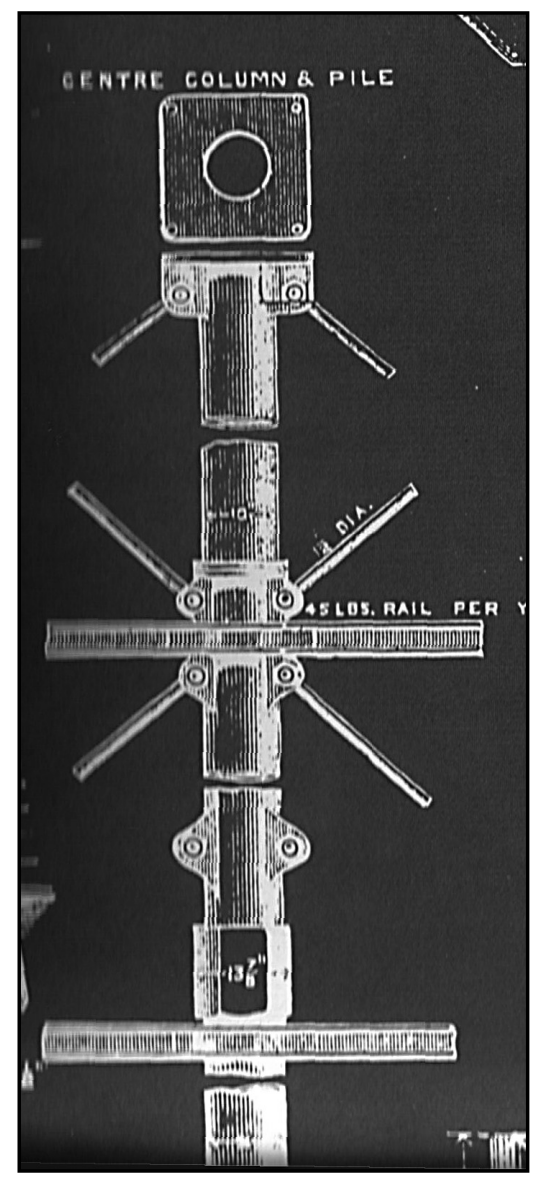

Figura 3. Barras atornilladas en pilares del muelle de Ramsgate.

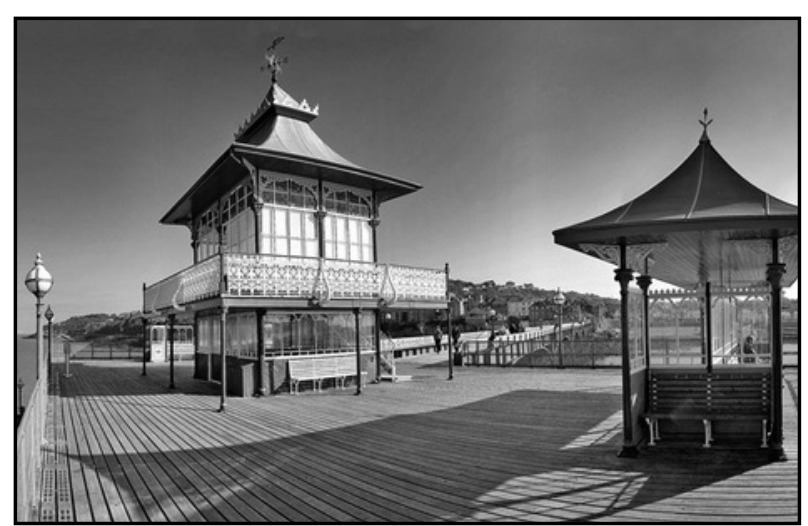

Figura 4. Pabellones construidos en el extremo del muelle de Clevedon.

Los pilotes de hierro fundido eran fáciles de fabricar, dada la importancia de la industria de la fundición en Gran Bretaña en el XIX. También eran fáciles de instalar, debido al desarrollo de la ingeniería en aquella época. Sus secciones, circulares o elípticas, ofrecían escasa resistencia al agua y al embate de las olas, y sus cimentaciones profundas no repercutían en la alteración del fondo marino, como en el caso de los muelles instalados sobre plataformas de roca u hormigón. Además eran resistentes a la corrosión y esbeltos y bellos en su diseño.

Se había encontrado el material ideal, al menos para los pilotes de cimentación y las columnas de los embarcaderos, aunque no era así en lo referente a vigas y tableros de la estructura. La fundición tenía poca resistencia a flexión y, por tanto, a tracción en la cara inferior de las vigas, similar a la de la madera, pero con un peso muy superior. Además resultaba frágil frente a golpes y vibraciones, que podía recibir con frecuencia en las cubiertas de los muelles. Pero pronto aparecería el nuevo material que venía a resolver definitivamente el problema: el hiero forjado, del que nos ocupamos más adelante.

El hierro fundido o colado tiene una temperatura de fusión de $1200^{\circ} \mathrm{C}$. La experiencia británica nos informa de que la composición idónea para obtener la mejor fundición gris es la que tiene un 3,20\% de carbono, un $2 \%$ de silicio, un $1 \%$ de manganeso, un $0,15 \%$ de azufre y un $0,20 \%$ de fósforo.

\section{CARACTERÍSTICAS Y PROPIEDADES DEL HIERRO FORJADO}

El hierro forjado es uno de los resultados de la metalurgia del mineral de hierro. El proceso implica la fusión del mineral en hornos adecuados hasta llevarlo a un contenido relativamente bajo de carbono (entre el 1 y el $2 \%$ ), y la aplicación al hierro resultante de un tratamiento a base de golpeo, para proporcionarle una estructura fibrosa 
que aumenta su resistencia y homogeneidad. La forja incrementa asimismo la compacidad del hierro, lo que le da mayor resistencia a la corrosión. El calentamiento del metal hasta el rojo vivo elimina carbono por combustión y mejora sus condiciones. Y además, este estado semifluido que alcanza el hierro al calentarlo hasta la incandescencia, permite modificar su forma por el golpeo y unir piezas por soldadura mecánica. La forja necesita por tanto de fraguas y hornos para caldear, y de la aplicación de una corriente de aire que avive el combustible y eleve la temperatura del hierro situado en el hogar.

Las herramientas de los talleres de forjado permiten dar al hierro un tratamiento de estirado, estampado, doblado, aplastado, soldado por incandescencia, etc.. También se pueden aplicar al hierro forjado tratamientos de recocido, enfriado, temple, etc., que logran mejorar aún más sus condiciones hasta convertirlo en acero. Es de considerar que la laminación es una de las variedades de la forja, ya que consiste en un tratamiento de aplastamiento mecánico por presión y estiramiento hasta espesores predeterminados, bajo temperaturas altas, que se aplican lo mismo al acero que al hierro forjado para mejorar sus condiciones y controlar sus dimensiones.

El hierro forjado provenía en general de la fundición, por eliminación de carbono bajo temperaturas altas y corrientes de aire. Si se continuaba el tratamiento se podía llegar a la eliminación total del carbono, produciéndose hierro dulce, blando, maleable, muy oxidable y de propiedades magnéticas. Controlando el proceso de la proporción del carbono en el hierro, se llegaba a producir acero si el contenido en carbono era del 0,15 al 1\%.

El hierro forjado tiene aproximadamente la misma resistencia a tracción que a compresión, lo que representaba en aquella época una ventaja importantísima sobre el hierro fundido, que a tracción no podía superar los $23 \mathrm{~N} / \mathrm{mm}^{2}$. Además se unía tanto por roblonado o atornillado como por soldadura incandescente y golpeo, lo que suponía haber encontrado el material perfecto para la tracción. Por el contrario, resultaba más caro que la fundición y era más oxidable por lo que no llegó a desbancar a la fundición en elementos a compresión, sobre todo en soportes y columnas, ya que esta era más barata, igualmente resistente a la compresión y de mejor comportamiento ante la oxidación.

Pero la asociación de ambos materiales constituyó la fórmula casi perfecta para la ingeniería británica. Los grandes puentes combinaban sabiamente la fundición y el hierro forjado con espectaculares resultados, y otras magníficas realizaciones, impulsadas por la era de las exposiciones universales, asombraron al país. La mayor obra de la Exposición Universal de Londres de 1851 fue sin duda el Cristal Palace, obra colosal de John Paxton (Figura 5). Se trataba de un gigantesco pabellón cubierto de una extensión de 7 ha (560 m de largo, 124 de ancho y 33 de altura) instalado en el Hyde Park, y en cuyo interior se celebraba la gran muestra. Se ejecutó en ocho meses, en estructura prefabricada y desmontable, de pilares de fundición, vigas de hierro forjado y cerramientos y cubiertas de cristal. En 1854 se desmontó y se trasladó a Sydenham Hill, donde permaneció instalado hasta 1936 , en que un incendio lo destruyó.

Con estos antecedentes, y los ya sabidos problemas de la madera, a partir de la mitad del siglo XIX, la mayoría de los embarcaderos británicos se construían en hierro y tenían los pilares y columnas de fundición mientras que sus vigas principales y secundarias eran de hierro forjado. El hierro forjado era muy apreciado y algunas estructuras se construyeron completamente en este material, como el embarcadero de Clevedon. No obstante, la fundición seguía resultando más duradera y barata en elementos verticales y su empleo en esta posición fue generalizado.

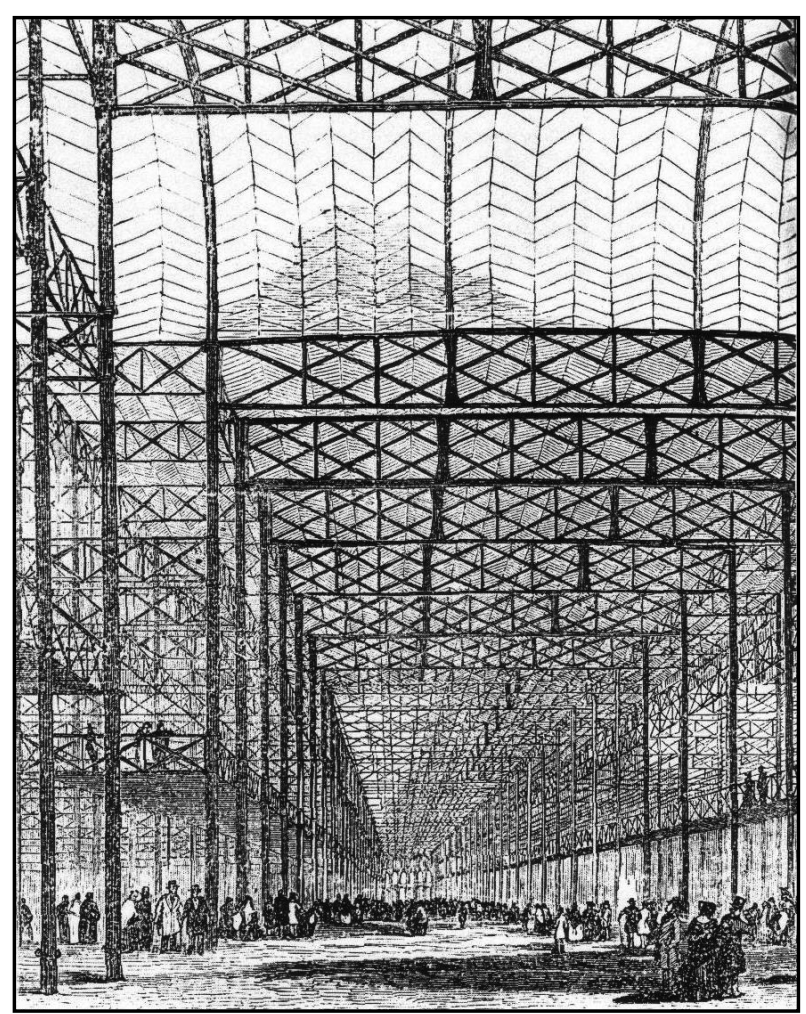

Figura 5. Estructura del Cristal Palace.

\section{LAS TENSIONES DE TRABAJO DE LA FUNDICIÓN Y DEL HIERRO FORJADO EN GRAN BRETAÑA A LO LARGO DE LA HISTORIA}

El hierro fundido empezó a utilizarse en estructuras de puentes y embarcaderos sobre 1850, y se siguió utilizando industrialmente hasta la década de 1920, fecha en la 
que el uso de ambos materiales en estructuras metálicas languideció, sustituidos por el acero.

La primera normativa británica que proporciona datos sobre las características técnicas de la fundición y del hierro forjado es de 1859 (Board of Trade Requirement), si bien su uso no era preceptivo ya que, aunque se facilitaban unas recomendaciones al efecto, quedaban a criterio de los ingenieros las tensiones a aplicar a estos materiales en cada caso.

No es hasta 1909 cuando aparece la primera norma de obligado cumplimiento al respecto, la General Powers Act, del London County Council. En ella se establecen unas determinadas tensiones de trabajo (8) para el hierro fundido y el hierro forjado, según se indica en la Tabla 1.

Tabla 1

Tensiones del hierro fundido y del hierro forjado.

\begin{tabular}{|c|c|c|}
\hline Material & Tn / Pulgadas & $\mathbf{N} / \mathbf{m m}^{\mathbf{2}}$ \\
\hline Fundición a compresión & 8,0 & 123,6 \\
\hline Fundición a tracción & 1,5 & 23,2 \\
\hline Fundición a cortante & 1,5 & 23,2 \\
\hline Hierro forjado a compresión & 5,0 & 77,2 \\
\hline Hierro forjado a tracción & 5,0 & 77,2 \\
\hline Hierro forjado a cortante & 4,2 & 61,8 \\
\hline
\end{tabular}

En el año 1967, el Department of Transport's Standard de Londres publica la instrucción BE-4 en la que se establecen nuevos valores para las tensiones admisibles en ambos materiales, que se muestran en la Tabla 2.

Tabla 2

Departamento de normativa BE-4 para el transporte. Londres, 1967.

\begin{tabular}{|c|c|c|}
\hline Material & Tn / Pulgadas $^{\mathbf{2}}$ & $\mathbf{N} / \mathbf{m m}^{\mathbf{2}}$ \\
\hline Fundición a compresión & 10,00 & 154,50 \\
\hline Fundición a tracción & 2,20 & 34,00 \\
\hline Fundición a cortante & 2,20 & 34,00 \\
\hline Hierro forjado a compresión & 8,40 & 129,78 \\
\hline Hierro forjado a tracción & 8,40 & 129,78 \\
\hline Hierro forjado a cortante & 6,70 & 103,51 \\
\hline
\end{tabular}

Finalmente, el mismo organismo publica una nueva instrucción en 1984, actualmente en vigor en el Reino Unido (9), y denominada BD-21/84, muy similar a la de 1967, y que se acompaña en la Tabla 3. En ella puede observarse que, con respecto a los datos de 1909, en la fundición se han elevado las primitivas tensiones admisibles hasta en un $47 \%$ mientras que en el hierro forjado estas elevaciones llegan a ser de un $84 \%$, sin duda por un mejor conocimiento del comportamiento de estos materiales, lo que condujo a reducir los coeficientes de seguridad (en un principio establecidos en 4 o 5) a niveles sensiblemente inferiores.
Tabla 3

Departamento de normativa BE-21/84 para el transporte. Londres, 1984.

\begin{tabular}{|c|c|c|}
\hline Material & Tn / Pulgadas $^{2}$ & $\mathbf{N} / \mathbf{m m}^{\mathbf{2}}$ \\
\hline Fundición a compresión & 10,00 & 154,50 \\
\hline Fundición a tracción & 2,20 & 34,00 \\
\hline Fundición a cortante & 2,20 & 34,00 \\
\hline Hierro forjado a compresión & 9,10 & 151,00 \\
\hline Hierro forjado a tracción & 9,10 & 141,00 \\
\hline Hierro forjado a cortante & 7,28 & 111,48 \\
\hline
\end{tabular}

\section{UN CASO PRÁCTICO. LA RESTAURACIÓN DEL MUELLE DE RIOTINTO EN HUELVA}

En el año 1980 el Instituto Nacional de Calidad en la Edificación, por encargo de la Junta de Andalucía, llevó a cabo el primer estudio acerca del estado de la estructura del muelle de Riotinto, construido en Huelva en 1874 por la Riotinto Company Limited para embarque del mineral procedente de las minas de Riotinto. La estructura del embarcadero estaba ejecutada con columnas de fundición, jácenas de hierro forjado en celosía (Figura 6), y sobre ellas la cubierta de jácenas y piso de entablado de madera. Del análisis realizado se deducía que las columnas de fundición se encontraban en general en buen estado (no habían perdido ni el $10 \%$ de su sección en los elementos más afectados), mientras que las jácenas de hierro forjado se encontraban muy deterioradas en el nivel 0 , entre mareas, y en mejor estado en los niveles superiores (10). La estructura de madera se encontraba en estado de ruina, por lo que fue desmontada.

En el año 1992 se redactó un proyecto de reparación de la estructura metálica del embarcadero para el que se analizaron de nuevo pilares y jácenas obteniéndose el mismo resultado (11). Otro trabajo de distintos autores publicado en 1993 en la revista British Corrosion Journal (12) establece las mismas conclusiones en general,

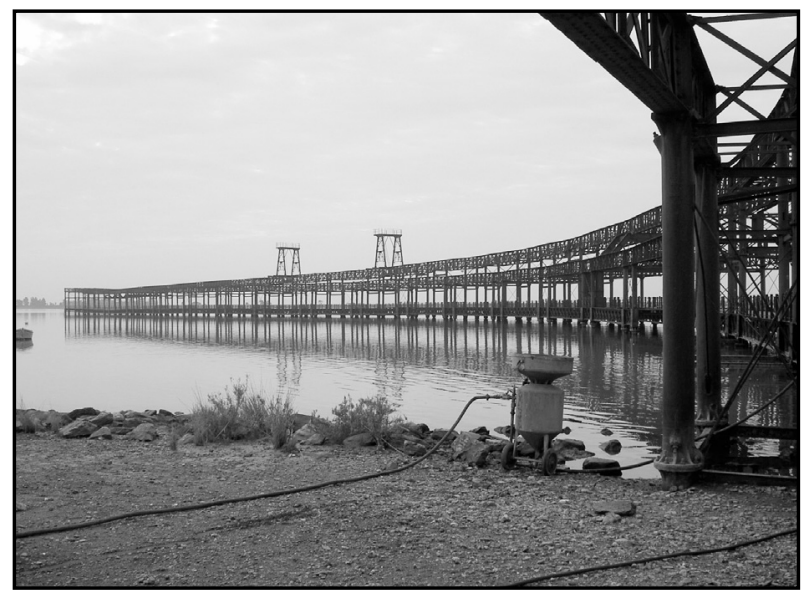

Figura 6. Embarcadero de Riotinto en Huelva. 
señalando la alta resistencia a la corrosión demostrada por la fundición en un medio tan agresivo, teniendo en cuenta además la acidez de las aguas de la ría de Huelva. En este trabajo se manifiesta asimismo la protección efectiva, ejercida a lo largo de un siglo, del primitivo recubrimiento de alquitrán de hulla de $10 \mathrm{~mm}$ de espesor aplicado sobre el hierro forjado, y que había conseguido preservar de la corrosión a la mayor parte de la estructura del muelle, salvo en la zona entre mareas.

El proyecto de 1992 mantiene las vigas de celosía de los niveles superiores, y sustituye las del nivel inferior por otras similares ejecutadas en acero, disponiéndose cartelas en los nudos. Es de señalar que en menos de 20 años, la corrosión de los cordones inferiores de estas jácenas ha sido considerable, con una velocidad muy superior a la de corrosión del hierro forjado (Figura 7).

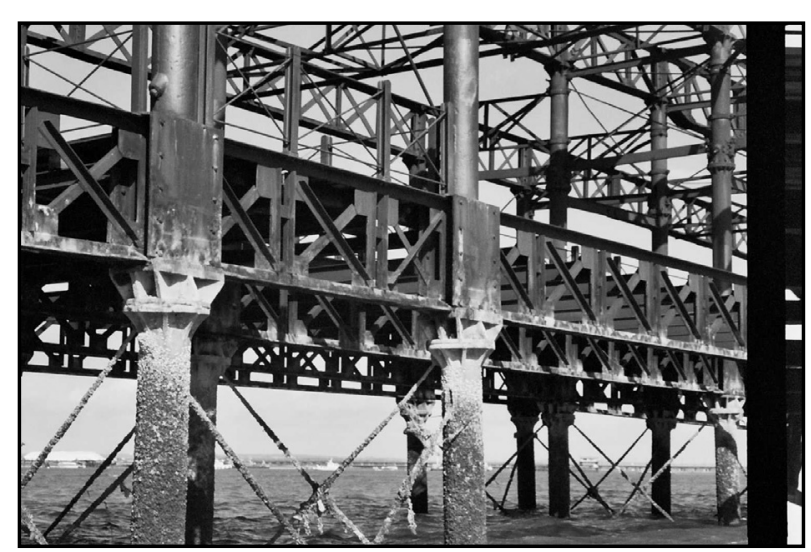

Figura 7. Corrosión en jácenas nivel cero, en el muelle de Riotinto.

Finalmente, entre los años 2001 y 2004, se ha redactado un nuevo proyecto y se han llevado a cabo las obras de restauración de la parte del muelle en tierra, y las de terminación de la parte marítima del mismo. En este proyecto (13) se establecen las siguientes conclusiones con respecto al estado de la estructura del embarcadero en el año 2001:

Los pilares de fundición se encontraban en buen estado, con corrosiones de escasa importancia. Asimismo, salvo en algún caso puntual, no se observaban roturas frágiles en dichas piezas. No fue necesario sustituir ninguno de los pilares existentes, aunque sí reforzar con collarines alguna basa fisurada.

Las jácenas de celosía de acero del nivel entre mareas, colocadas hacía menos de diez años, aparecían afectadas sensiblemente por corrosión, obligando a sustituciones locales de algunas de sus barras pero en cambio se mantuvieron, con algunas reparaciones puntuales, las primitivas jácenas de hierro forjado de los niveles superiores, en los que la corrosión era poco significativa, pudiendo deducirse que el comportamiento del hierro forjado contra la corrosión, aunque sin llegar a los excelentes niveles de la fundición, había sido satisfactorio.

\section{CONCLUSIONES}

De la exposición llevada a cabo deducimos la importancia que los muelles embarcaderos adquieren en el siglo XIX, como grandes estructuras costeras sometidas a condiciones ambientales adversas, y como campo de experimentación de nuevos materiales para resistir estas circunstancias. Y ponemos de manifiesto la importancia que adquieren desde 1850 la fundición y el hierro forjado como elementos novedosos en la construcción de estas estructuras.

Se exponen en el presente trabajo las características resistentes de la fundición y el hierro forjado en los inicios de su aplicación al mundo de las estructuras, así como su trayectoria y la actualidad de la que todavía disfrutan en el campo de la ingeniería y de la construcción modernas.

Y se aportan datos de las determinaciones técnicas y de los trabajos de restauración llevados a cabo en el muelle de Riotinto, en Huelva, en los que se demostró el excelente comportamiento frente a la corrosión, después de más de un siglo, del hierro fundido de sus columnas, siendo aceptable también el comportamiento del hierro forjado de sus jácenas, superior al del acero estructural recientemente empleado en la restauración.

\section{BIBLIOGRAFÍA / BIBLIOGRAPHY}

(1) Adamson, Simon H.: Seaside Pier (1977), Londres.

(2) González García de Velasco, C. y González Vílchez, M.: La problemática de la construcción y conservación de los embarcaderos de madera en el siglo XIX. Libro de Actas del VI Congreso de Historia de la Construcción (2009), Valencia.

(3) Mickleburgh, T.: Glory Days Piers (1999), Londres.

(4) Mitchell, A.: On Submarine Foundations; particulary the Screw Pile and Moorings (1848), Institution of Civil Engineers, Minutes of Proceedings, Londres. 
(5) Benevolo, L.: Historia de la Arquitectura Moderna (1974), Barcelona.

(6) Rooker, W.: Papers from the Pier Symposium (Department of Environment. The National Piers Society). Cast Iron and the Coalbrookdale Company (1984), Londres.

(7) Allwood, A.: Papers from the Pier Symposium (Department of Environment. The National Piers Society). Widnes Foundry and Engineering Co. Ltd. (1984), Londres.

(8) Sutherland, R. J.: Structural Aspects of Building Conservation. Paul Beckman et al. Cambridge, 2004.

(9) Sutherland, R. J.: Studies in the History of Civil Engineering (1998), Variorum, Londres.

(10) Instituto Nacional de la Calidad en la Edificación: Estudio sobre el estado actual del Muelle de Riotinto (1980), Dirección General de Arquitectura. Junta de Andalucía.

(11) Puntas Aguilar, J. L.: Estudio de la Estructura y Reparación del Muelle de Riotinto (1992), ETSI, Sevilla.

(12) Herrera, E. J. et al.: "Corrosion on Riotinto Pier at Huelva", British Corrosion Journal (1993), vol. 28, no 4.

(13) Freyssinet, S. A.: Proyecto de reparación del muelle de Riotinto (2001-2004). 